\title{
Optimal Synthesis of Energy Efficient Distillation Columns Sequence Using Driving Force Method
}

\author{
Ahmad Nafais Rahimi ${ }^{1,2}$, Mohd. Faris Mustafa ${ }^{1,2}$, Muhammad Zakwan Zaine ${ }^{1,2}$, Norazana Ibrahim ${ }^{3}$, Kamarul \\ Asri Ibrahim ${ }^{1,2} \&$ Mohd. Kamaruddin Abd. Hamid ${ }^{1,2}$ \\ ${ }^{1}$ Process Systems Engineering Centre (PROSPECT), Research Institute of Sustainable Environment (RISE), \\ Malaysia \\ ${ }^{2}$ Department of Chemical Engineering, Faculty of Chemical Engineering, Malaysia \\ ${ }^{3}$ UTM-MPRC Institute of Oil \& Gas, Faculty of Petroleum and Renewable Energy Engineering, Universiti \\ Teknologi Malaysia, Malaysia \\ Correspondence: Mohd. Kamaruddin Abd. Hamid, UTM-MPRC Institute of Oil \& Gas, Faculty of Petroleum \\ and Renewable Energy Engineering, Universiti Teknologi Malaysia, 81310, UTM Johor Bahru, Johor, Malaysia. \\ E-mail: kamaruddin@cheme.utm.my
}

Received: May 4, 2015

Accepted: June 5, 2015

Online Published: June 30, 2015

doi:10.5539/mas.v9n7p154

URL: http://dx.doi.org/10.5539/mas.v9n7p154

\begin{abstract}
This paper presents the study of the optimal synthesis of energy efficient distillation columns (EEDCs) sequence by using the driving force method. In order to perform the study and analysis, the EEDCs sequence methodology has been developed. Accordingly, the methodology consists of four hierarchical sequential steps; Step 1: Existing Sequence Energy Analysis, Step 2: Optimal Sequence Determination, Step 3: Optimal Sequence Energy Analysis, and Step 4: Energy Comparison. The capability of this methodology has been tested in designing minimum energy distillation column sequence for hydrocarbon mixture separation process. The results show that the maximum of $39.6 \%$ energy reduction was able to achieve by changing the sequence suggested by the driving force method. It can be concluded that, the sequence determined by the driving force method is able to reduce energy requirement for hydrocarbon mixture separation process. All of this findings show that the methodology is able to design minimum energy distillation column sequence for hydrocarbon mixture separation process in an easy, practical and systematic manner.
\end{abstract}

Keywords: energy efficient, distillation columns sequence, driving force method, energy analysis

\section{Introduction}

The production of a set of product stream from a feed hydrocarbon mixture is a basic task in the natural gas processing. The objective is to obtain products that are sufficiently pure for further usage and conversion, and also to carry out this separation task with a minimum cost and energy consumption. The primary process for separation is a distillation column unit which is widely used since it has many advantages. On the negative side, this primary process requires a large energy that can significantly influence the overall plant profitability. There is no denying fact that energy considerations will have a more significant impact on the distillation column design and retrofitting in the future. The determination of feasible sequences of multiple distillation columns, whether on the basis of minimum overall energy consumption, total annualized costs, sustainability, or some other metric, has been the subject of academic and industrial investigation for many years.

A large number of researches have been conducted to focus the advantages of a variety of methodologies for determining the best sequence from a given number of component in the feed mixture. These include early methodologies such as the use of heuristics, genetic algorithms, mixed integer nonlinear programming (MINLP) methods and others (Lucia, 2010). According to Grosmann et al. (1999), distillation column continues to be the most significant separation technique not only for nonideal mixtures but also for azeotropic mixtures even on the negative side it is a quite expensive operation in terms of capital and operating costs. (Westerberg, 1985), (Floquet et al., 1988; 1994) and (Gert-Jan et al., 1994) proposed a general review of distillation column synthesis. Heuristic methods (Seader \& Westerberg, 1977), evolutionary techniques (Stephanopoulus \& Westerberg, 1976), superstructure optimization (Floudas, 1995) and graphical methods (Mustafa et al., 2014) are several approaches 
to design efficient separation systems.

In the heuristic method, the objective is to help to determine the more economical sequences without require to do a column design and also cost analysis. There are various reviews on distillation columns sequence synthesis by using heuristics such as (Nagdir \& Liu, 1983), (Tedder \& Rudd, 1978) and (Rudd et al., 1973). In heuristic method, several steps need to be considered are as follows: (1) thermally unstable, corrosive or chemically reactive components is removed early in the sequence, (2) final products is removed one-by-one as distillates (the direct sequence), (3) sequence separation points to remove, early in the sequence, those components of greatest molar percentage in the feed, (4) separation points is sequenced in the order of decreasing relative volatility so that the most difficult splits are made in the absence of other components, (5) separation points is sequenced to leave last those separations that give the highest purity products, (6) separation points that favor near equimolar amounts of distillate and bottoms in each column is sequenced (Seider, Seader and Lewin 2004). Alternatively, cost estimation method (Modi \& Westerberg, 1992) could be done for each column since possible sequences obtained from the heuristic methods are potentially uncertain or may conflicting.

Besides heuristic, optimization methods can be used to find efficient distillation sequence (Floudas, 1987; Wehe \& Westerberg, 1987). According to (Floudas, 1987), all possible configurations of separation tasks will be embedded through superstructure which is used to extract the desired sequence by a nonlinear programming problem. To produce multicomponent products from a single multicomponent feed through minimum number of columns using a nonsharp separation sequence, a bounding procedure could be used (Wehe \& Westerberg, 1990).

The graphical method can be categorized into several categories which are McCabe-Thiele, driving force and pinch technology which can be used to determine the optimal design of distillation columns. To determine the design values of distillation column in a simple technique, the McCabe-Thiele has been proposed (Wang et al., 1994). In distillation column, driving force is the difference between composition in vapor phase and liquid phase as a result of difference of properties such as boiling point and vapor pressure (Bek-Pedersen \& Gani, 2004). (Kemp, 2007) proposed pinch technology method which produces minimum energy usage as part of the energy monitoring.

However, the conventional distillation column may be used in hydrocarbon mixture separation design, and only the configurations/sequences need to be changed. Since the multiple products produced by the hydrocarbon mixture separation process and because of the large amount of energy required, hydrocarbon mixture separation process provides several opportunities for the economical process improvement. This can be systematically and effectively achieved by using driving force method.

Generally, driving force is applied in multicomponent systems that has varies physical or chemical properties between different phases will existing together. In distillation column, the driving force can be shown by facing distinction in composition of a component $i$ between the vapour and liquid phase due to the difference of properties such as boiling point and vapour pressure of component $i$ and the others. Driving force can be measured by the binary pair of key multi-component mixture or binary mixture. In theoretical, when the driving force near to zero the separation of the key component binary mixture becomes difficult, while, when the driving force near to high peak or maximum value, the separation between two components become more easier. Through a systematic synthesis of energy integrated distillation column systems, external energy input can be reduced and as a result the heat exchange between the integrated columns is maximized (Sobocan et al., 2012).

In this paper, the study and analysis of the energy saving improvement for the hydrocarbon mixture separation sequence by using driving force method without having any major modifications to the major separation units, is presented. There will be only modifications to the separation sequences based on the driving force results, which will reduce the energy requirement. To perform the study and analysis, the energy efficient distillation columns (EEDCs) sequence methodology is developed. Accordingly, the methodology consists of four hierarchical steps. In the first step, a simple and reliable short-cut method is used to simulate a base (existing) columns sequence. The energy used in the base sequence is taken as a reference. In the second stage, an optimal columns sequence is determined by using driving force method. All individual driving force curves is plotted and the optimal sequence is determined based on the plotted driving force curves. Then, by using a short-cut method, the new optimal sequence is simulated in step three, where the energy used in the optimal sequence is analyzed. Finally, the energy used in the optimal sequence is compared with the base sequence. We will demonstrate some energy saving distillation columns sequence and demonstrate how the use of driving force method helps in determining the optimal sequence with less energy requirement. 


\section{Nomenclature}

MINLP Mixed Integer Nonlinear Programming

EEDCs Energy Efficient Distillation Columns

\section{Energy Efficient Distillation Columns Sequence Methodology}

To perform the study and analysis of the energy saving improvement for the energy efficient hydrocarbon mixture separation sequence, EEDCs sequence methodology is developed based on the driving force method. Accordingly, the methodology consists of four hierarchical steps as shown in Figure 1.
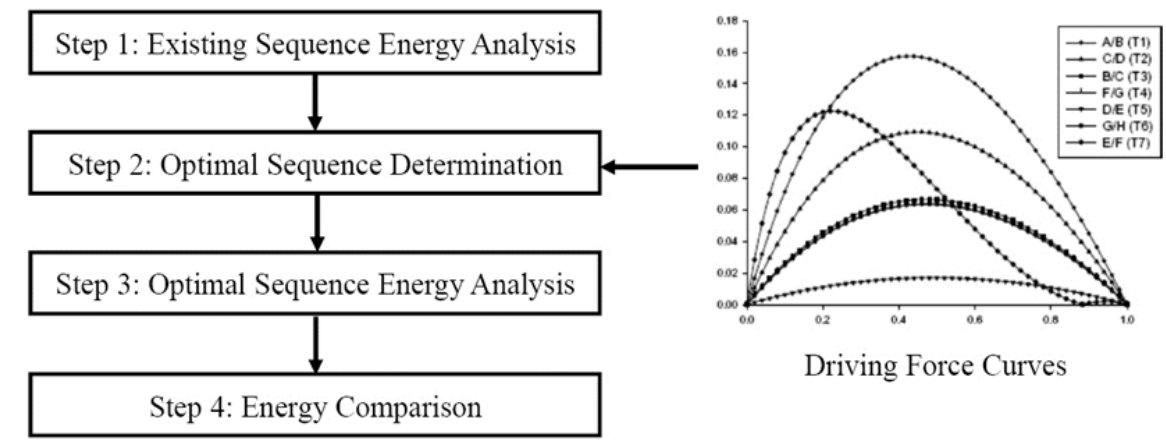

Figure 1. Energy efficient distillation columns sequence methodology (Mustafa et al., 2014)

The objective of the hydrocarbon mixtures fractionation process is to recover individual fractions of hydrocarbon mixtures by using a distillation columns hydrocarbon mixtures, which normally have significantly greater value as separate marketable products than that as part of the natural gas stream. Light hydrocarbon mixtures fractions, propane, $i$-butane and $n$-butane, can be sold as fuel or feedstock to refineries and petrochemical plants, while the heavier fractions can be used as gasoline-blending stock. The hydrocarbon mixtures fractionation process consists of eleven compounds (propane, $i$-butane, $n$-butane, $i$-pentane, $n$-pentane, $n$-hexane, benzene, cyclohexane, $n$-heptane, toluene, and $n$-decane).

In the first step, a simple and reliable short-cut method of process simulator (Aspen HYSYS) is used to simulate a base (existing) columns sequence. The energy used to recover individual fractions in the base sequence is analyzed and taken as a reference. In the second stage, an optimal columns sequence is determined by using driving force method. All individual driving force curves for all adjacent components are plotted and the optimal sequence is determined based on the plotted driving force curves. The highest value of maximum driving force which corresponds to the splitting of the adjacent component will be separated first, while the lowest value of the maximum driving force will be separated last.

According to the driving force method, separation becomes simple and the energy required to maintain the separation is at the minimum when the value of driving force is maximum. Whereas, at the lowest value of the maximum driving force, separation becomes difficult and energy required to make the separation feasible is at the maximum (Bek Pedersen \& Gani, 2004). Once the optimal sequence has been determined, the new optimal sequence is then simulated in step three by using a simple and reliable short-cut method (using Aspen HYSYS), where the energy used in the optimal sequence is analyzed. Finally, the energy used in the optimal sequence is compared with the base sequence. The capability of this methodology is tested in designing minimum energy distillation column sequence for hydrocarbon mixture separation process, which consists of 11 compounds (propane, $i$-butane, $n$-butane, $i$-pentane, $n$-pentane, $n$-hexane, benzene, cyclohexane, $n$-heptane, toluene, $n$-decane) with 10 direct sequence distillation columns.

\section{Case Study: Hydrocarbon Mixture Separation Process}

The capability of proposed methodology is tested in designing minimum energy distillation column sequence for 
hydrocarbon mixture separation process. The objective of the hydrocarbon mixture separation process is to recover individual fractions using a distillation columns. Existing hydrocarbon mixture separation process consists of 11 compounds (propane, $i$-butane, $n$-butane, $i$-pentane, $n$-pentane, $n$-hexane, benzene, cyclohexane, $n$-heptane, toluene, $n$-decane) with 10 direct sequence distillation columns.

\subsection{Existing Sequence Energy Analysis}

Figure 2 illustrates the existing separation sequence of the hydrocarbon mixture separation process. The feed composition, temperature and pressure are described in Table 1. The existing hydrocarbon mixture separation process was simulated using a simple and reliable short-cut method within Aspen HYSYS environment. A total of $249.1 \mathrm{MW}$ energy used to achieve $99.9 \%$ of product recovery.

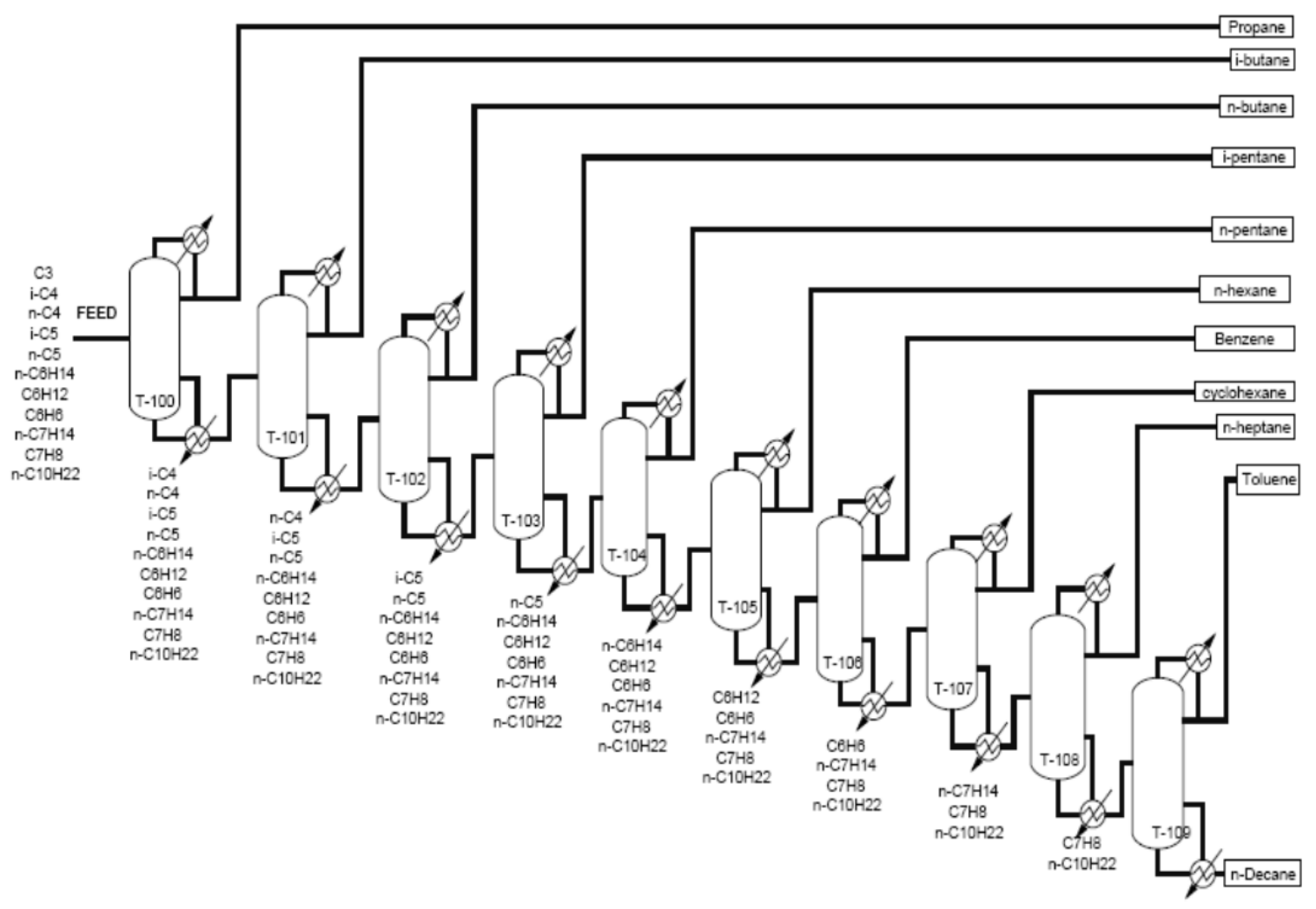

Figure 2. Simplified flow sheet illustrating the existing direct sequence of hydrocarbon mixture separation process

Table 1. Feed conditions of the mixture

\begin{tabular}{lll}
\hline & \multicolumn{2}{l}{ Feed conditions } \\
\cline { 2 - 3 } Components & Molar flow (lbmol/h) & Mole fractions (\%) \\
\hline Propane (A) & 148.2 & 5.7 \\
$i$-Butane (B) & 91.0 & 3.5 \\
$n$-Butane (C) & 239.2 & 9.2 \\
$i$-Pentane (D) & 135.2 & 6.7 \\
$n$-Pentane (E) & 174.2 & 5.2 \\
$n$-Hexane (F) & 218.4 & 8.4 \\
Benzene (G) & 65.0 & 2.5 \\
Cyclohexane (H) & 101.4 & 3.9 \\
$n$-Heptane (I) & 288.6 & 11.1 \\
Toluene (J) & 426.4 & 16.4 \\
$n$-decane (K) & 712.4 & 27.2 \\
Temperature ( $\left.{ }^{\circ} \mathrm{F}\right)$ & & 150 \\
Pressure (psia) & & 200 \\
\hline
\end{tabular}




\subsection{Optimal Sequence Determination}

The optimal hydrocarbon mixture separation sequence is determined by using driving force method. All individual driving force curves is plotted as shown in the Figure 3, and the optimal sequence is determined based on the plotted driving force curves. The new sequence based on driving force is shown in the Figure 4 .

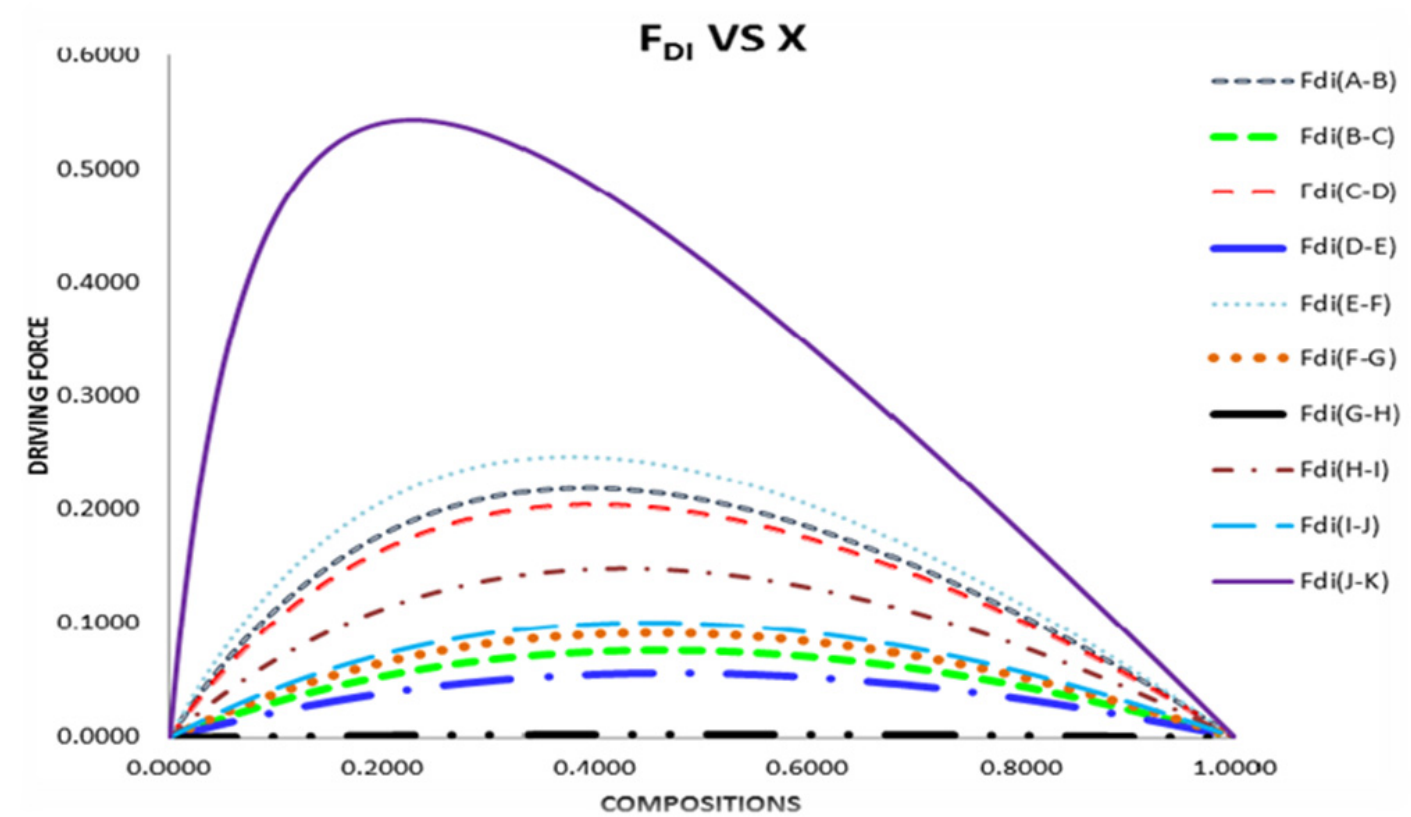

Figure 3. Driving Force curves for set of binary component at uniform pressure for hydrocarbon mixture

\subsection{Optimal Sequence Energy Analysis}

A new optimal sequence determined by driving force method (see Figure 4) is simulated using a short-cut method within Aspen HYSYS environment where a total of 150.5 MW of energy is used for the same product recovery.

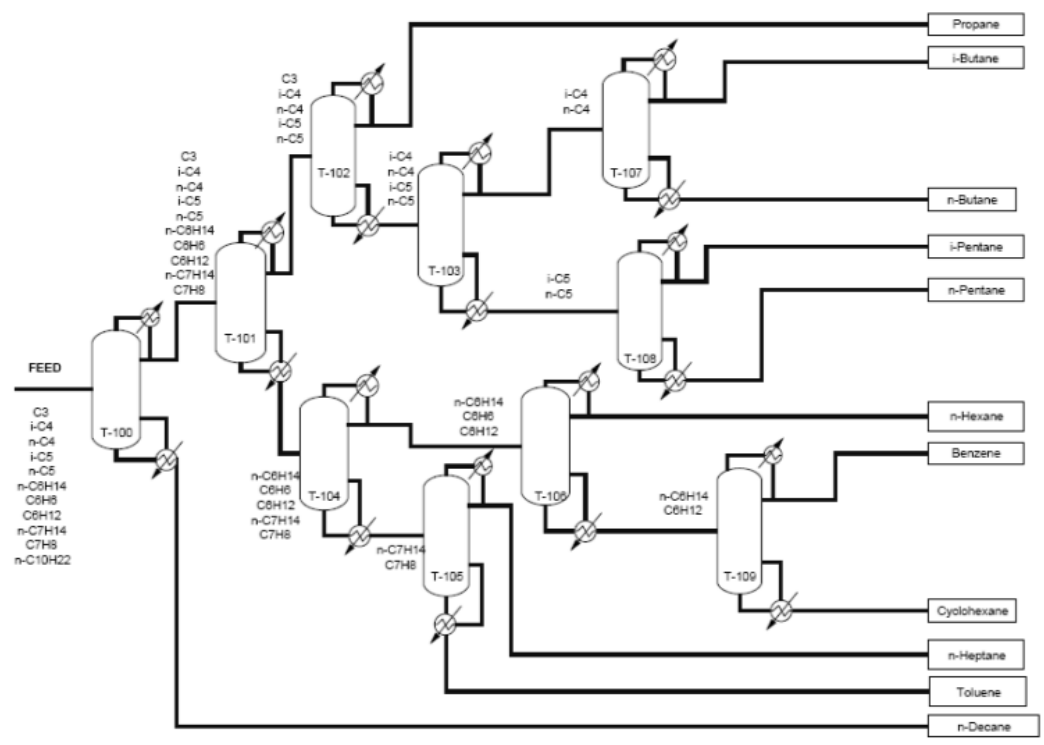

Figure 4. Simplified flow sheet illustrating the optimal Driving Force sequence of hydrocarbon mixture separation process 


\subsection{Energy Comparison}

Total energy used to recover every single fractions for the existing direct sequence and the new optimal sequence determined by the driving force method is shown in Table 2. The results show that the maximum of $39.6 \%$ energy reduction was able to achieve by changing the sequence suggested by the driving force method. It can be concluded that, the sequence determined by the driving force method is able to reduce energy used for hydrocarbon mixture separation process.

Table 2. Energy comparison for direct sequence and driving force sequence for hydrocarbon mixture separation process.

\begin{tabular}{llll}
\hline & Direct Sequence & Driving Force Sequence & Percentage (\%) \\
\hline Total Energy Condenser (MW) & 108.9 & 68.0 & $\mathbf{3 7 . 5}$ \\
Total Energy Reboiler (MW) & 140.2 & 82.5 & $\mathbf{4 1 . 2}$ \\
Total Energy (MW) & $\mathbf{2 4 9 . 1}$ & $\mathbf{1 5 0 . 5}$ & $\mathbf{3 9 . 6}$ \\
\hline
\end{tabular}

\section{Conclusion}

The study and analysis of the energy saving improvement for the hydrocarbon mixture separation process by using driving force method has been successfully performed. The existing hydrocarbon mixture separation process consists of 11 compounds (propane, $i$-butane, $n$-butane, $i$-pentane, $n$-pentane, $n$-hexane, benzene, cyclohexane, $n$-heptane, toluene, $n$-decane) with 10 direct sequence distillation columns was simulated using a simple and reliable short-cut method within Aspen HYSYS environment. A total of 249.1 MW energy used to achieve $99.9 \%$ of product recovery. A new optimal sequence determined by driving force method was simulated using a short-cut method within Aspen HYSYS environment where a total of $150.5 \mathrm{MW}$ of energy was used of the same product recovery. The results show that the maximum of $39.6 \%$ energy reduction was able to achieve by changing the sequence suggested by the driving force method. It can be concluded that, the sequence determined by the driving force method is able to reduce energy used for hydrocarbon mixture separation process in an easy, practical and systematic manner.

\section{Acknowledgements}

The financial support from Universiti Teknologi Malaysia (RUGS Tier 1 Q.J130000.2509.07H39) and Ministry of Education of Malaysia FRGS (R.J130000.7809.4F435) are highly acknowledged.

\section{References}

Bek-Pedersen, E., \& Gani, R. (2004). Design and Synthesis of Distillation Systems Using a Driving-Force Based Approach. Chemical Engineering and Processing, 43, 251-262. http://dx.doi.org/10.1016/S0255-2701(03)00120-X

Floquet, P., Pibouleau, L., \& Domenech, S. (1988). Mathematical Programming Tools for Chemical Engineering Process Design Synthesis. Chem. Eng. Process, 23. http://dx.doi.org/10.1016/0255-2701(88)80004-7

Floquet, P., Pibouleau, L., \& Domenech, S. (1994). Separation Sequence Synthesis: How to use Simulated Annealing Procedure? Comp. Chem. Eng., 18, 1141. http://dx.doi.org/10.1016/0098-1354(94)e0023-g

Floudas C. A. (1987). Separation synthesis of multicomponent feed streams into multicomponent product streams. AIChE J., 33(4), 540-550. http://dx.doi.org/10.1002/aic.690330403

Floudas, C. A. (1995). Nonlinear and Mixed-Integer Optimization: Fundamentals and Applications. Oxford University Press

Gert-Jan, A. F., \& Liu, Y. A. (1994). Heuristic Synthesis and Shortcut Design of Separation Processes Using Residue Curve Maps: A Review. Ind. Eng. Chem. Res., 33, 2505. http://dx.doi.org/10.1021/ie00035a001

Grossmann, E. I., Caballero, A. J., \& Yeomans, H. (1999). Advances in Mathematical Programming for Automated Design, Integration and Operation of Chemical Processes. Department of Chemical Engineering argegie Mellon University Pittsburgh, PA 15213, USA.

Juergen, K., Poellmann, P., \& Blass, E. (1995). A Review on Minimum Energy Calculations for Ideal and Nonideal Distillations. Ind. Eng. Chem. Res., 34, 1003. http://dx.doi.org/10.1021/ie00043a001

Kemp, I. C. (2007). Pinch Analysis and Process Integration. A User Guide on Process Integration for the Efficient Use of Energy. Elsevier, Amsterdam, the Netherlands. 
Long, N. V. D., \& Lee, M. (2011). Improved Energy Efficiency in Debottlenecking using a Fully Thermally Coupled Distillation Column. Asia-Pac. J. Chem. Eng., 6, 338-348. http://dx.doi.org/10.1002/apj.577

Lucia, A., \& McCallum, B. R, (2010). Energy targetting and minimum energy distillation column sequences.Computers and Chemical Engineering, 34, 931-942. http://dx.doi.org/10.1016/j.compchemeng.2009.10.006

Modi, A., \& Westerberg, A. (1992). Distillation column sequencing using marginal price. Industrial \& Engineering Chemistry Research, 31(3), 839-848. http://dx.doi.org/10.1021/ie00003a028

Mustafa, M. F., Abdul Samad, N. A. F., Ibrahim, K. A., \& Hamid, M. K. A. (2014). Methodology Development of a Flexible and Operable Energy Integrated Distillation Columns. $3^{\text {rd }}$ International Conference on Process Engineering and Advanced Materials (ICPEAM 2014), KLCC, Kuala Lumpur (pp. 490-493). http://dx.doi.org/10.4028/www.scientific.net/amm.625.490

Mustafa, M. F., Abdul Samad, N. A. F., Ibrahim, N., Ibrahim, K. A., \& Hamid, M. K. A. (2014). Energy Efficient Distillation Columns Design for Retrofit NGLs Fractionation Process. The $2^{\text {nd }}$ International Conference on Global Sustainability and Chemical Engineering (ICGSCE2014), Kuala Lumpur. August (pp. 20-22).

Nadgir V. M., \& Liu Y. A. (1983). Studies in chemical process design and synthesis: Part V: A simple heuristic method for systematic synthesis of initial sequences for multicomponent separation. AIChE J., 29(6), 926-934. http://dx.doi.org/10.1002/aic.690290609

Rudd, D. F., Powers G. J., \& Siirola, J. J. (1973). Process Synthesis. Prentice-Hall, Englewood Cliffs, NJ.

Seader, J. D., \& Westerberg, A. W. (1977). A combined heuristic and evolutionary strategy for synthesis of simple separation sequences. AIChE Journal, 23(6), 951-954. http://dx.doi.org/10.1002/aic.690290609

Seider, W. D, J. D., Seader, J. D., \& Lewin, D. R. (2004). Product and Process Design Principles: Synthesis, Analysis, and Evaluation (2nd ed.). John Wiley \& Sons (Asia) Pte Ltd.

Sobocan, G., \& Glavic, P. (2012). A simple method for systematic synthesis of thermally integrated distillation $\begin{array}{llll}\text { sequences. } & \text { Chemical } & \text { Engineering }\end{array}$ $\mathrm{http}: / / \mathrm{dx}$.doi.org/10.1016/S1385-8947(02)00012-8

Stephanopoulos, G., \& Westerberg, A. W. (1976). Studies in Process Synthesis-II. Evolutionary Synthesis of Optimal Process Flowsheets. Chem. Eng. Scl., 31, 195. http://dx.doi.org/10.1016/0009-2509(76)85057-9

Tedder, D. W., \& Rudd, F. D. (1978). Parametric studies in industrial distillation: Part I. Design comparisons. AIChE Journal, 24(2), 303-315. http://dx.doi.org/10.1002/aic.690240220

Wang, J. L., \& Mansoori, G. A. (1994). A Revision of the Distillation Theory (Part I). Scientia Ir., 1(3), 267-287.

Wehe, R. R., \& Westerberg, A. W. (1990). A bounding procedure for the minimum number of columns in nonsharp distillation sequences. Chem. Eng. Sci., 45(1). http://dx.doi.org/10.1016/0009-2509(90)87075-4

Westerberg, A. W. (1985). The Synthesis of Distillated Based Separation. Comp. Chem. Eng., 9(421).

\section{Copyrights}

Copyright for this article is retained by the author(s), with first publication rights granted to the journal.

This is an open-access article distributed under the terms and conditions of the Creative Commons Attribution license (http://creativecommons.org/licenses/by/3.0/). 